\title{
A imaterialidade do trabalho do jogador de futebol: uma interpretação teórica
}

\author{
Aldo Antonio de Azevedo \\ Doutor em Sociologia (UnB) \\ aldoazevedo@uol.com.br
}

\begin{abstract}
Resumo Este artigo apresenta uma interpretação teórica do trabalho do jogador de futebol valendo-se da noção de trabalho imaterial. Embora o ofício do jogador de futebol apresente em sua caracterização aspectos quantificáveis e mensuráveis do trabalho material, como salário, contrato de trabalho, jornada de trabalho que se reduz a treinamentos e jogos, etc; existem elementos subjetivos, imensuráveis e não-quantificáveis, que podem ser interpretados sob duas dimensões analíticas, a saber: a) a do sujeito que trabalha; b) a do produto do trabalho. Desse modo, na atividade do jogador de futebol o talento esportivo do sujeito constitui um ponto central a ser considerado, uma vez que se converte no principal produto do trabalho e da inteligência coletiva: o espetáculo esportivo.
\end{abstract}

Palavras-chave: trabalho imaterial; trabalho material; talento esportivo; espetáculo esportivo; jogador de futebol.

\section{Introdução}

$\mathrm{O}$ PRESENTE TEXTO DisCUTE TEORICAMENTE a atividade do jogador de futebol profissional valendo-se da noção de trabalho imaterial. Parte-se do pressuposto de que na atividade do jogador existem características quantificáveis e mensuráveis, que indicam uma predominância do trabalho material e, em outras, elementos não mensuráveis e quantificáveis, do trabalho imaterial. Não existe, portanto, uma relação de determinação absoluta de uma ou outra forma de trabalho, mas de predominância.

Também, com base nessa premissa, acredita-se que qualquer análise ou interpretação de uma das formas, seja ela a imaterialidade ou materialidade, depende de um contraponto com a outra. Desse modo, acredita-se que a atividade do jogador de futebol envolve, não apenas o trabalho físico do corpo, como treinamentos, uma jornada de trabalho, salário e um contrato, que constituem, genericamente, bases do trabalho material; mas aspectos da subjetividade humana, como o dom, para alguns, ou talento, para outros, a imagem do jogador e a produção do espetáculo, que caracterizam o trabalho imaterial.

$\mathrm{O}$ interesse pelo debate sobre o tema teve origem no estudo sobre a relação futebol - empresa no Brasil, realizado em nossa Tese de Doutorado, em 1999, da docência em Sociologia do Esporte e da participação no Grupo de Estudos e Pesquisas sobre o Trabalho (GEPT), do Departamento de Sociologia da Universidade de Brasília (UnB) (Azevedo, 1999).

Atualmente, no Brasil, o futebol vem sendo abordado por diversas áreas do conhecimento, em especial, pelas Ciências Sociais, além de ocupar espaço também, nas artes, como cinema, teatro, música etc. 
Como atividade, incorpora as características do esporte como o rendimento, a competição, o resultado, as regras codificadas internacionalmente e a luta contra um oponente direto usando o corpo físico, fatores estes que implicam, a princípio, em sua interpretação sob a ótica do trabalho material.

É sabido que o esporte possui relevância significativa nas sociedades em diversos setores, como cultura, grupos e classes sociais, organizações, instituições, relações sociais etc. ${ }^{1}$ No Brasil, o futebol, de modo especial, vem sendo abordado por diversas áreas do conhecimento como as Ciências Sociais, além de ocupar espaço também em campos como cinema, teatro, música, política, economia etc.

Como atividade, o futebol incorpora características conceituais do esporte como rendimento, competição, regras codificadas internacionalmente, luta contra um oponente direto usando o corpo físico na busca por um resultado (Brohm, 1976) ${ }^{2}$, que traduzem, a princípio, uma interpretação sob a ótica do trabalho material. No caso brasileiro pode-se afirmar que o futebol é considerado muito mais como jogo, em que elementos como sorte, azar, drama, emoções, por exemplo, são componentes a serem considerados em suas análises ${ }^{3}$ (Da Matta, 1982, 1986; Guedes, 1977).

Alia-se, ainda, a esse contexto de interpretação, o fato do futebol, hoje, ser também um campo de trabalho para os jogadores, por razões históricas e sociais como, por exemplo, a popularização e até mesmo a democratização da prática por todo o país, independente de classe social, raça e sexo. Sabe-se que, historicamente, até a década de 30, do século XX, o futebol sempre foi um espaço de lazer dos aristocratas filhos de imigrantes europeus, que instalaram suas fábricas e indústrias no início desse século. Só a partir de 1933, o futebol deixa de ser uma prática das elites, para se popularizar e se tornar, posteriormente, trabalho para os jogadores. No caso brasileiro é considerado muito mais como jogo, onde elementos como sorte, azar, drama, emoções, o talento do jogador e a inteligência coletiva, por exemplo, são componentes a serem considerados em suas análises.

Embora o imaginário popular alimente a idéia de que jogador de futebol é um privilegiado e ganha um alto salário, a realidade concreta demonstra que o futebol é um universo de desempregados da bola. Desse modo, na esfera da concepção de jogo, acredita-se que o talento, a visibilidade na televisão e a relação jogador-empresário constituem elementos sociológicos estruturantes do trabalho imaterial do jogador.

Nessa perspectiva específica, duas dimensões ana- líticas são elucidativas, a saber: a) a do sujeito que trabalha; b) a do produto do trabalho. Desse modo, duas indagações surgem como centrais: como podemos interpretar o trabalho imaterial sob a ótica do trabalho do jogador de futebol ? O que o jogador produz com o seu trabalho?

No que diz respeito ao referencial teórico, recorreu-se, inicialmente, aos estudos marxistas acerca da relação capital versus trabalho, expressos em seus textos clássicos - O capital, A ideologia alemã e os Grundrisse. Também, num segundo momento, às atuais interpretações acerca da imaterialidade do trabalho, tida como uma nova vertente de análise daquela relação, expressa nas contribuições de Lazzarato; Negri (2001), Gorz (2005), Imbrizi (2005), Romero (2005), Codo e colaboradores (1993) entre outros.

\section{Sobre o conceito de trabalho imaterial}

O próprio Marx, em seus escritos, já havia feito uma previsão de mudanças no capitalismo e, em especial, na esfera do trabalho, idealizando o surgimento de uma forma avançada em relação ao trabalho abstrato simples, da época de Adam Smith, que era considerado como fonte de valor. A mensuração e quantificação da produção em relação ao tempo gasto, paulatinamente, passam a ser substituídos por uma complexidade crescente em termos de padrões. Aliás, nos Grundrisse, Marx apontava que o conhecimento se tornaria a principal fonte de riqueza e que o trabalho imediato, quantificável e mensurável deixariam de ser a medida dessa riqueza criada, e esta dependeria cada vez menos do tempo e da quantidade de trabalho requeridos, exigindo mais do nível geral da ciência e do progresso da tecnologia.

Também, a partir de 1980, no entendimento de alguns autores que estudaram as recentes transformações no mundo do trabalho, o período de vinte anos de reestruturação produtiva levou à derrota do chamado operário fordista e trouxe à tona a centralidade de um trabalho vivo cada vez mais intelectualizado, que constituiu as bases do trabalho pós-fordista. $\mathrm{Na}$ perspectiva de transformação da sociedade, o trabalho no modelo fordista de produção passou a prescindir das capacidades intelectuais humanas ocupando-se da produção de bens e produtos de consumo, como o trabalho imaterial avançou ao mobilizar aspectos das relações intelectuais e afetivas do trabalhador ao pro-

1 Estudo amplo e elucidativo sobre esse significado social do esporte encontra-se em McPherson (1989).

2 Tais elementos constituem um dos conceitos mais tradicionalmente aceitos de esporte na perspectiva da sociedade capitalista e em suas relações com a política e a ideologia.

3 Estes estudos apresentam elementos que nos permitem fazer interpretações do futebol como um jogo que se insere no cotidiano da vida cultural e social dos indivíduos. 
duzir bens imateriais para o consumo, como informação, necessidades, valores, cuidado, conforto, tranqüilidade, sentimento de bem-estar, e interação humana etc. (Grisci, Hofmeister; Cigerza, 2006, p. 245).

Esses argumentos justificam, a princípio, a hegemonia do trabalho imaterial do operário social, nova categoria de operário ou proletário que surge no pósfordismo. Nesse cenário, a noção de trabalho imaterial assume relevância e elementos convergentes são aqui apontados por alguns autores.

Cattani; Holzmann (2006, p. 327), genericamente, entendem por trabalho imaterial, "o conjunto de atividades corporais, intelectuais, criativas, afetivas e comunicativas inerentes ao trabalhador...", e disso resulta, além de produtos materiais, produtos intangíveis como sentimentos de confiança, segurança e conforto aos consumidores numa nova relação produçãoconsumo. Acrescenta-se a isso, ainda, o fato de que o produto do trabalho imaterial, ao ser consumido, não mais permanece com o seu consumidor como permaneceria o produto do trabalho material.

Para Lazzarato; Negri (2001, p. 45), do mesmo modo, a perspectiva da construção do conceito de trabalho imaterial encontra relações com o seu ciclo produtivo e com a subjetividade, entendendo esta última como estilos de vida ou modos de existência. O trabalho imaterial é aquele que incorpora todas as características da economia pós-industrial, presentes tanto na indústria quanto no setor terciário. Essas características são acentuadas na forma da produção imaterial propriamente dita. Atividades como a produção audiovisual, a publicidade, a moda, a produção de software, a gestão do território etc. são definidas e balizadas pela relação que a produção mantém com o mercado e os consumidores.

Com base no ponto de vista acima, podemos dizer que os campos midiáticos, como a televisão, a internet e os outros meios de comunicação que circundam e patrocinam o esporte da alta competição, como o futebol, por exemplo, constituem bases exteriores do trabalho imaterial do jogador, reforçando positivamente ou negativamente sua carreira e sucesso no mercado.

Sob o olhar de Gorz (2005, p. 9), o trabalho imaterial apresenta-se como uma espécie de economia do conhecimento do capitalismo, em que o trabalho, a produção industrial e o setor de serviços, incorporam um componente de saber, de relevância crescente, que é responsável pela redefinição de categorias centrais como valor, capital e trabalho. O saber a que nos referimos não se identifica com o saber que se compõe de um conjunto de conhecimentos específicos formais que podem ser aprendidos em escolas técnicas; mas o saber constituído por um componente comportamental, que é a motivação para a qualidade da produção. Esse saber, na linguagem empresarial, é denominado capital humano.
Entretanto, diferentemente do capital humano, o autor supracitado aponta o capital do conhecimento, que já é uma forma existente e tão antiga quanto o próprio capitalismo industrial. Essa forma de capital quanto mais se propaga e se desenvolve, agrega maior utilidade à sociedade e, contrariamente, menor valor mercantil; mas para ser vendido como mercadoria e ser aproveitado como capital, esse conhecimento deve se transformar em propriedade privada e tornar-se escasso.

Segundo Gorz (2005, p. 10), o saber não se permite ser manipulado como mercadoria; pois, os custos da sua produção muitas vezes não podem ser determinados. Também, seu valor mercantil não pode ser mensurado de acordo com o tempo de trabalho necessário gasto em sua criação.

Acrescenta, ainda, o autor que:

Ninguém é capaz de dizer com precisão onde, no contexto social, o inventivo trabalho do saber começa, e onde termina. Ele pode estar numa atividade de lazer, num hobby, num serviço extra. Aliás, não existe uma relação de equivalência entre formas de saber e conteúdos: eles são intercambiáveis. Todo saber pode valer por um valor particular único e incomparável. Porém é exatamente o que tem de incomparável que acaba sendo utilizado pelo capital (Gorz, 2005, p. 10-11).

No que se refere ao saber do jogador que trabalha como profissional de futebol, o incomparável é o que distingue e se traduz como uma qualificação individual: o talento esportivo. É esse talento que converte o jogador em mercadoria e os elementos para mensurá-lo não são materiais.

Embora seja inevitável dizer e admitir que o corpo físico é o fundamento do trabalho, por excelência, o que implica na pessoalidade do jogador; concordase com Gorz (2005, p. 16), quando ele entende que:

$O$ valor encontra hoje sua fonte na inteligência e na imaginação. $\mathrm{O}$ saber do indivíduo conta mais que o tempo da máquina. O homem, carregando consigo seu próprio capital, carrega igualmente uma parte do capital da empresa.

Embora não seja pretensão fazer a apologia do "treinar para quê, se eu já sei o que fazer", em alusão a uma música que faz referência ao jogador Romário, não importa apenas o treinamento racional, intenso, metódico e progressivo, que tem suas bases científicas, que possui padrões clássicos de medida. Do mesmo modo, a técnica, por si só, não é condição suficiente, sem se fazer acompanhar da inteligência (para jogar), imaginação, saber e criatividade, que caracterizam alguns jogadores brasileiros que são muito valorizados no mercado do futebol.

Talvez se encontre aqui a justificativa para a difi- 
culdade com que se fixa o preço do passe de um jogador nesse mercado. Para muitos, o atacante vale mais que o defensor; pois, fazer gol é o objetivo do jogo ou do espetáculo; do mesmo modo, ter boa técnica, mas, acima de tudo, talento.

Ainda, a respeito do trabalho imaterial, Gorz (2005) é enfático ao expor suas características; e, ao mesmo tempo, admite que os jogos e esportes contém um conteúdo de saber, que é necessário ao trabalho social pós-fordista:

O coração, o centro da criação de valor, é o trabalho imaterial. [...] ele repousa sobre as capacidades expressivas e cooperativas que não se podem ensinar, sobre uma vivacidade presente na utilização dos saberes e que faz parte da cultura do cotidiano. Essa é uma das grandes diferenças entre os trabalhadores de manufaturas ou de indústrias taylorizadas e aqueles do pós-fordismo. Os trabalhadores pós-fordistas, ao contrário, devem entrar no processo de produção com toda a bagagem cultural que eles adquiriram nos jogos, nos esportes de equipe, nas lutas, disputas, nas atividades musicais, teatrais etc... É nessas atividades fora do trabalho que são desenvolvidas sua vivacidade, sua capacidade de improvisação, de cooperação. É seu valor vernacular que a empresa pós-fordista põe para trabalhar, e explora (Gorz, 2005, p. 19).

\section{A imaterialidade e o sujeito que trabalha}

$\mathrm{Na}$ esfera do sujeito que trabalha, antes de enfocar o trabalho imaterial, não há como abstrair elementos da materialidade; pois, envolve diretamente o trabalho físico ou do corpo físico. Desse modo, a atividade do jogador é uma atividade física, onde usa do seu corpo físico nos treinamentos e nos jogos. Aqui, de início, pode-se dizer que há um predomínio da forma trabalho material. O corpo do jogador é o objeto do trabalho, que se assemelha com o chamado trabalho braçal; ou com o trabalho dos garis ao recolherem o lixo nas residências, os motoristas de coletivos, os operários da construção civil etc.

No entanto, há um aspecto imaterial, que se refere aos elementos do afetivo (grupos de jogadores em colaboração e entre-ajuda) e intelecto - (a inteligência esportiva que demarca a qualidade, a técnica e o estilo do jogador para atuar no campo de jogo, que podese denominar como talento esportivo). Cabe lembrar, porém, que existem jogadores no mercado e com sucesso profissional, sem ter necessariamente esses re- quisitos. Há casos em que a liderança, o desempenho e o comportamento exemplar do jogador, são suficientes para a sua colocação no mercado de trabalho, ainda que não possuam talento esportivo.

Há uma estreita relação entre a concepção de subjetividade e a esfera do trabalho. Desse modo, entende-se com Imbrizi (2005), que a subjetividade do trabalhador incorpora em seu estudo as categorias expropriação e apropriação, advindas da teoria da revolução de Marx. Faz parte desse estudo, ainda, a noção de afeto, não no sentido freudiano do termo, mas com significado de mediação, vinculação e afetação, que em última instância traduzem uma linguagem simbólica ou fusão dialética no processo de produção.

Os estudos de Codo e colaboradores (1993, p. 190), no entanto, acrescentam que se, antes, nas comunidades primitivas e durante a escravidão, havia uma fusão entre afeto e trabalho, de modo que não se podia falar de uma distinção entre a estrutura produtiva e reprodutiva, hoje, há, na verdade, uma cisão entre o afeto e o trabalho; pois, "existe sempre uma transferência de subjetividade ao produto: trabalhar é impor a nossa face, o mundo fica mais parecido conosco e, portanto, nossa subjetividade depositada ali fora de nós, nos representando".

De qualquer forma, pode-se dizer que com o advento do capitalismo foram postas as condições desta cisão, conforme as condições formais dessa ruptura entre sujeito e objeto e do sujeito consigo mesmo, também se estabeleceram por intermédio da mídia televisiva e da internet. É nesse contexto que surge o homem alienado (Meszáros, 2006, p. 130-138).

Assim, do mesmo modo que o mundo do trabalho e o mundo do afeto se desenvolveram nos universos distintos das fábricas ou indústrias e o lar, o esporte, em especial, o trabalho do jogador de futebol acompanhou tal transformação. Guardadas as devidas proporções, no que se refere ao processo produtivo, entre a fábrica e o time de futebol, quando o modo de produção isola o produtor de seu produto, verifica-se uma transformação no trabalho e nas subjetividades.

O trabalho é transformado em força de trabalho e o seu produto em mercadoria, abstraindo a subjetividade humana desse produto. No futebol, o espetáculo (produto imaterial do trabalho) apresenta-se, portanto, como um objeto de consumo que é apropriado ou expropriado dos sujeitos que, de fato, o produzem: os jogadores.

No entanto, no futebol, para reproduzir-se socialmente, ter ascensão social e sucesso na profissão, o jogador também passa a fazer parte do consumo do espetáculo. Também, a questão do afeto não é a única a constituir a subjetividade humana do jogador no seu trabalho no futebol. A imagem que produz de si mesmo ou sua visibilidade na mídia, fazem parte desse es- 
paço de produção e reprodução da sua identidade. Estas faces estão funcionalizadas pela idéia de fetichismo, mas numa perspectiva muito mais individual do que coletiva, pois, a questão do talento e a visibilidade na mídia pertencem à subjetividade do indivíduo, ainda que este faça parte de um grupo esportivo (time de futebol).

\section{O produto do trabalho imaterial}

O resultado industrial do trabalho traduz-se por duas formas distintas: o produto material e o produto imaterial. De fato, no esporte e, em especial, no futebol, o mesmo pode ser dito.

Genericamente, o produto material ou objeto produzido pelo trabalho, por exemplo, poderia ser uma cadeira, uma mesa, uma lata de graxa etc. No caso do trabalho do jogador, o treinamento físico, a participação em um jogo que resulta em vitória, derrota ou empate, seriam produtos materiais do trabalho de um jogador de futebol. Desse modo, a essência, na perspectiva do que se produz, é o trabalho material. Aqui, há uma relação de correspondência entre o sujeito que trabalha e o produto desse trabalho, em que o corpo físico é o objeto ou a via de acesso à produção. Essa produção é o movimento corporal e a técnica.

No que se refere ao ciclo da produção imaterial (Lazzarato; Negri, 2001, p. 44), apontam que a grande indústria, a empresa e a economia pós-industrial estão assentadas sobre o tratamento da informação. As características de uma nova integração entre consumo e produção, desenvolvem as chamadas relações de serviço como informação, necessidades dos consumidores, valores, interação entre os seres humanos, subjetividades etc.

Negri e Hardt (2005, p. 149), por sua vez, apresentam algumas características da produção do trabalho imaterial, que se divide em duas categorias, a saber: o trabalho intelectual ou lingüístico (idéias, símbolos, códigos, produtos culturais etc.); e, o trabalho afetivo (excitação, paixão, emoções, subjetividades etc.), onde podemos encontrar elementos que estão presentes na atividade do jogador de futebol e na própria produção do espetáculo.

Conforme Romero (2005, p. 71), na explicação sobre o produto do trabalho, deve-se considerar a subsunção formal $1^{5}$ do trabalho ao capital e ao processo de cooperação que envolve a produção, como inserido no trecho abaixo:

A categoria de trabalho social ganha uma dimensão mais abrangente e mais concreta. A socialização do trabalho já é realizada por meio do capital; a cooperação simples propicia num sentido fundante, a socialização do trabalho como socialização do capital, as forças produtivas do trabalho como forças produtivas do capital: como pessoas independentes, os trabalhadores são indivíduos que entram em relação com o mesmo capital, mas não entre si. Sua cooperação começa só no processo de trabalho, mas no processo de trabalho eles deixam de pertencer a si mesmos. Com a entrada no mesmo, eles são incorporados ao capital. Como cooperadores, como membros de um organismo que trabalha, eles não são mais do que um modo específico de existência do capital. A força produtiva que o trabalhador desenvolve como trabalhador social é, portanto, força produtiva do capital (Romero, 2005, p. 71).

No que se refere ao processo de cooperação é útil entender que, embora o resultado seja o trabalho social - produzido a partir da inserção do trabalhador assalariado no interior das unidades produtivas da socialização do trabalho - o que é efetivamente pago é o trabalho individual.

Daí, conforme Romero (2005, p. 77), entende-se diretamente a subsunção do trabalho ao capital, pois:

... como é o capitalista quem emprega os trabalhadores em grande número, concentra-os sob um mesmo teto e organiza a produção em seu conjunto; como também é o capitalista que tem a propriedade dos meios de produção e estes, por isso, aparecem frente ao trabalhador como condições alheias; por tudo isso, esta capacidade do trabalho de produzir mais mediante sua combinação parece como um fator que se origina não do próprio trabalho, mas, agora, do capital.

Nesses termos, acredita-se que, na esfera da produção do espetáculo no futebol, a cooperação representa elemento essencial a esse processo de subsunção.

Aliás, Gorz (2005, p. 17) também identifica que neste novo processo do capital, na "sociedade da inteligência" (Knowledge society), o saber é feito de experiências e de práticas que se transformam em evidências intuitivas, hábitos; e a inteligência cobre todo o leque das capacidades que vão do julgamento e do discernimento à abertura de espírito, à aptidão de assimilar novos conhecimentos e de combiná-los com os saberes.

Com base nessas interpretações, percebe-se que o melhor jogador de futebol é aquele que combina capacidades, possui o saber; mas o saber criativo que o insere numa espécie de sociedade da inteligência esportiva. O conhecimento cognitivo, a técnica, o estilo, a capacidade de criação e improviso no campo de jogo 
e na produção do espetáculo, são essenciais para dizer que um jogador de futebol é um talento, de fato.

No que diz respeito ao produto do trabalho do jogador - o espetáculo - percebe-se que trata desta combinação de talentos individuais; mas, acima de tudo, o resultado final é de uma produção coletiva para o mercado. Comparando, por exemplo, com uma indústria informatizada, Gorz (2005), ao afirmar que trabalhar significa produzir-se, entende que a comunicação e a cooperação entre operadores é parte integrante para a qualidade das informações no sistema; e o tempo como padrão de valor não funciona mais, pois vale a subjetividade e a qualidade da coordenação desse sistema. O desempenho, portanto, depende, dos aspectos sistêmicos e das relações entre os indivíduos.

Nesse sentido, por analogia, a produção do espetáculo é coletiva e não é igual à soma dos talentos individuais, considerados isoladamente; mas à combinação e à coordenação entre os jogadores. Esse resultado é imaterial, intangível; mas produzido para o consumo.

Portanto, se, para um jornalista, por exemplo, o produto imaterial do seu trabalho seria a idéia ou o sentido que fica do seu texto material e jornalístico, e não todo o conjunto de letras gráficas; se, para um artesão, seria a satisfação pelo que produziu materialmente (uma cadeira artesanal, por exemplo) e que tem um valor imaterial para si mesmo; no caso do jogador, sua atividade material ou participação como um trabalhador da bola, durante um jogo de futebol, resulta na produção imaterial espetáculo. Sob essa forma, o esporte se converte em mercadoria para ser vendida e consumida.

Não se pode, então, abstrair o fato da produção do espetáculo também ser obra do empresário. Aliás, refiro-me tanto aos empresários que promovem o espetáculo (patrocinadores e parceiros), promotores de evento, televisão etc.; como os empresários individuais de jogadores, que colocam suas mercadorias em exposição, para negociações com clubes nacionais e do exterior.

Nessa combinação produtiva, há que se levar em conta a substituição do físico pelo imaterial e a imposição de uma nova divisão do trabalho. Isso tem uma relação de correspondência como o fato de mega-empresas, como a Nike, por exemplo, ao lançarem sua marca nos uniformes dos jogadores, estão também promovendo sua marca pela substituição do físico pelo imaterial, ao mesmo tempo que essa marca será divulgada gratuitamente pela visibilidade da camisa na mídia. Do mesmo modo, tem-se uma divisão de trabalho, transferindo para o jogador e para a televisão o trabalho de divulgação da marca.

Aliás, Gorz (2005, p. 39) identifica estas mudanças fazendo referências à terceirização, valendo-se do abandono do capital material aos parceiros contratados pela firma-mãe, que os força a intensificar continua- mente a exploração de sua mão-de-obra. Nos termos do futebol, têm-se os pés-de-obra (jogadores), que são explorados e expostos na televisão para intensificar a divulgação da marca e promovem o grande espetáculo da firma-mãe: o consumo.

O espetáculo esportivo para se converter em mercadoria exige profissionais especializados em diversos setores, entre os quais incluem-se os atletas profissionais que vendem sua força de trabalho. Nesse caso, observa-se que a intencionalidade e posse do movimento corporal humano são também apropriados pelos interesses do capital, que passam a ser seus novos detentores. Verifica-se, portanto, uma perda da autonomia dos atletas que produzem a mercadoria esporte-espetáculo. Embora sejam os protagonistas do espetáculo, este é deles abstraído por outros agentes do espetáculo, como produtores, vendedores e a mídia televisiva.

Enfim, o espetáculo como resultado do trabalho imaterial resultaria, portanto, de sinergias positivas ou, ainda, seria uma externalidade positiva, produzidas com base no talento esportivo e nas subjetividades dos jogadores, o que permitiria uma analogia com a noção de General Intellect.

\section{Talento esportivo e General Intellect: elementos para uma analogia}

Segundo Lazzarato e Negri (2001, p. 27), dois elementos são relevantes para fundamentar teoricamente a nova ordem do trabalho: a) a transformação do trabalho em trabalho imaterial e da força de trabalho em intelectualidade de massa (os dois aspectos são chamados por Marx, de General Intellect); b) a intelectualidade de massas pode transformar - se em um sujeito social e politicamente hegemônico.

À luz desta interpretação, há uma transformação radical do sujeito da produção, de modo que o trabalho imaterial assume a condição de base fundamental da produção pós-fordista e o General Intellect é a própria subjetivação do trabalho imaterial.

As características principais inseridas no trabalho imaterial são: a autonomia das sinergias positivas; os produtos ideológicos se convertem em mercadorias; o público assume relevância ao mesmo tempo que torna-se o modelo do consumidor (relação público/ cliente) - novos valores são agregados a esse novo formato de trabalho (Lazzarato; Negri, 2001, p. 38-39).

Embora muitos interpretem o trabalho físico no esporte como uma prática marginal, que isola o saber em relação ao fazer, que não envolve, a priori, o saber ou o intelecto, é certo que para jogar bem, ser o melhor, 
ter qualidade, ser craque, é preciso inteligência esportiva, o que aqui denominamos talento esportivo.

Segundo estudiosos da área do esporte e da Educação Física, o talento pode tanto ser um dom ou uma qualidade que pode ser aperfeiçoada. No Brasil, as discussões relativas à questão do talento encerram posicionamentos distintos. Os estudos de Rodrigues (1993, 1994) e Filho (2003), por exemplo, decorrem de interpretações literárias que sugerem a idéia de que o talento para jogar futebol é uma qualidade que nasce com o indivíduo.

Damo (2005), em sua Tese de Doutorado, apresenta posicionamento contrário ao entender que o indivíduo não nasce com o dom para jogar futebol, adquirindo tal condição com base em sua formação como jogador. Acrescenta, ainda, que na perspectiva do espetáculo esse dom se converte em talento para o mercado do futebol.

De acordo com estes conceitos genéricos de talento esportivo e de trabalho imaterial, entende-se que há uma analogia entre aquele conceito e a idéia de General Intellect. Não resta dúvida de que são os jogadores de talento que, com essa qualidade individual, subjetivam o trabalho e agregam valor ao espetáculo. Este último é produzido coletivamente por jogadores e empresários, convertido numa grande mercadoria a ser consumida por espectadores e telespectadores de futebol.

Para Lazzarato e Negri (2001), duas conseqüências são aí produzidas, a saber: a colocação de novos valores no trabalho, que resulta num deslocamento do produto ideológico em mercadoria, o que por sua vez desvia o imaginário social que produz as novas formas de vida social; e, o fato das formas de vida constituírem a fonte das inovações, que são marcadas pela criatividade.

Com base nessas observações, a transformação da atividade do jogador em trabalho imaterial e da força de trabalho em intelectualidade de massa, se opera com base no produto espetáculo para as massas resulta de uma composição de individualidades, que são os jogadores de talento, mas que os supera coletivamente.

A considerar o trabalho material, pode-se, inicialmente, afirmar, que, diferentemente de um jogador, um jornalista, por exemplo, teria o intelecto e o afeto muito mais predominantes no seu trabalho, do que o físico. Já um operário industrial teria o físico (força e influência do taylorismo) como predominante sobre o intelecto e o afeto. No entanto, se fizermos uma analogia com o General Intelect, dos escritos marxistas, veremos que o talento esportivo traduz um dos elementos da forma trabalho imaterial.

A idéia embutida na noção de General Intelect, nos Grundrisse, de Marx, é elucidativa, à proporção que permite interpretar o talento esportivo como algo vinculado à inteligência para jogar; ou seja, um fator que diferencia subjetivamente um jogador de outro, e faz dele uma mercadoria individual, que contribui para a criação de um produto imaterial do trabalho: o espetáculo.

\section{A materialidade histórica do passe}

A antiga Lei n. 6.354, de 2 de setembro de 1976, conhecida como Lei do Passe constituiu um indicador comum das manifestações do trabalho assalariado do jogador no futebol profissional no Brasil. Entretanto, historicamente, a referida lei não preconizou no seu espírito, a possibilidade de avanços nas relações trabalhistas jogador-clube, o que deu margem para a manutenção de interesses econômicos dos clubes, que ainda predominam no futebol. Essa lei se manteve em vigor por mais de 20 anos no Brasil, foi, praticamente, extinta pela aprovação da Lei Pelé, em abril de 1998, ainda bastante discutida no cenário do futebol brasileiro.

A Lei do Passe, no seu artigo $2^{\circ}$, definia como empregado o atleta profissional que praticar o futebol sob a subordinação da associação desportiva ou clube (empregador), mediante remuneração e contrato de trabalho. Ao empregado, nesses termos legalmente definidos, algumas normas protetoras da referida lei foram apontadas, em conformidade com a configuração jurídica do direito do trabalho, a saber: a) a 'pessoalidade', uma vez que o jogador empregado obriga-se, 'pessoalmente', a executar a função assumida de jogar futebol, não podendo fazer-se representar por outro; b) a 'onerosidade', na qual se caracteriza a remuneração ajustada entre as partes, de obrigação do empregador, sendo de todo inadmissível a prestação de serviços; c) a 'continuidade', uma vez que a lei protege aqueles que prestam serviços continuados, e não os que praticam o futebol de forma eventual ou esporádica. A 'vinculação' das partes tem de ser durável; d) a 'exclusividade', por meio da qual o empregado não pode vincular-se, concomitantemente, a outra associação desportiva ou clube; e e) a 'subordinação', que se verifica pela hierarquia às determinações do empregador, desde que elas não firam o contrato, as leis e os bons costumes (Barros, 2003, p. 166-201; Reis, 1985, p. 11).

Os termos jurídicos do contrato, portanto, apresentam uma rigidez no sentido da adesão do jogador ao clube, e os jogadores não têm participação alguma na organização administrativa do clube, nem possuem força de ação e pressão sindicais, embora a sindicalização esteja prevista no artigo n. 577 da Consolidação das Leis do Trabalho (CLT).

Portanto, o passe constitui um elemento material ao mesmo tempo que transforma o jogador de futebol numa mercadoria, num trabalhador que tem direitos e obrigações com o seu empregador. 


\section{Conclusão}

A interpretação teórica das relações entre o trabalho do jogador de futebol e o trabalho imaterial, nos permitiu, inicialmente, apontar algumas questões relevantes, a saber: a) na atividade do jogador a materialidade ou imaterialidade do trabalho estão presentes; b) o trabalho imaterial incorpora o talento, ainda que este seja uma característica individualizada e atemporal, que sempre marcou os grandes ídolos do futebol e os distinguiu em relação aos demais. Porém, entende-se que esse talento também passa a fazer parte de uma produção coletiva ou o produto de uma intelectualidade de massa, que é o espetáculo. O talento individual imaterial depende da inteligência coletiva do grupo.

Fica claro, ainda, que não existe, portanto, uma relação de determinação absoluta de uma ou outra forma de trabalho, mas de predominância.

Conforme valoriza novas subjetividades, a visibilidade na televisão (necessários à conversão do jogador em mercadoria) e a produção do espetáculo, a forma da imaterialidade do trabalho se realiza. E, sob o signo da mercadoria, pode-se compreender, ainda, como o jogador transforma-se num patrimônio dos clubes e de empresários particulares. Essa é a lógica que predomina hoje, em razão do grande volume de negócios que permeiam o futebol e seus espetáculos no mundo, muito embora o trabalho corporal do jogador, dialeticamente, também seja necessário à imaterialidade da sua imagem no mercado.

Também, com base nessa premissa, acredita-se que qualquer análise ou interpretação de uma das formas, seja ela a imaterialidade ou materialidade, depende de um contraponto com a outra. De qualquer forma, o jogar futebol exige tanto o corpo físico quanto elementos intelectuais. Não há aqui fragmentação ou separação entre esses elementos.

O talento esportivo é uma qualidade individual que permite distinguir um jogador de outro e incorpora critérios como conhecimento, genialidade, habilidade, criatividade, estilo, técnica etc.; que se identificam aos requisitos exigidos hoje no mundo do trabalho. Desse modo, quando produz o espetáculo, o talento constitui parte de um produto coletivo, que se assemelharia à inteligência coletiva ou General Intellect.

\section{Referências}

AZEVEDO, Aldo. Dos velhos aos novos cartolas: uma interpretação do poder e das suas resistências nos clubes, face ao impacto das relações futebol-empresa. Tese (Doutorado em Sociologia). Brasília, Universidade de Brasília, 1999.

BARROS, Alice M. As relações de trabalho no espetáculo. São Paulo: Ltr, 2003.

BROHM, Jean-Marie. Sociologie politique du sport. Paris: Jean-Pierre Delarge éditeur, 1976. 357 p.

CATTANI, Antonio; HOLZMANN, Lorena. Dicionário de trabalho e tecnologia. (Org.). Porto Alegre: Ed. da UFRGS, 2006.

CODO, et al. Indivíduo, trabalho e sofrimento: uma abordagem interdisciplinar. 2. ed. Petrópolis: Vozes, 1993.

DA MATTA, Roberto (Org.). Universo do futebol: futebol e sociedade brasileira. Rio de Janeiro: Edições Pinakotheke, 1982.

Exploraçoes: ensaios de sociologia interpretativa. Rio de Janeiro: Rocco, 1986. 147 p.

DAMO, Arley S. Do dom à profissão. Tese (Doutorado em Antropologia) - Rio Grande do Sul: Instituto de Filosofia e Ciências Humanas, 2005, 435p.

FILHO, Mário. O negro no futebol brasileiro. 4. ed. Rio de Janeiro: Mauad, 2003. 343 p.

GRISCI; HOFMEISTER; CIGERZA. Trabalho imaterial, controle e subjetividade na reestruturação bancária. In: PICCININI; HOLZMANN; KÓVACS; GUIMARÃES (Orgs.). Mosaico do trabalho na sociedade contemporâ- nea: persistências e inovações. Porto Alegre: Editora da UFRGS, 2006. 359p.

GORZ, André. O imaterial: conhecimento, valor e capital. Tradução de Celso Azzan Júnior. São Paulo: Annablume, 2005.

GUEDES, Simone. O futebol brasileiro: instituição zero. Dissertação (Mestrado em Antropologia Social) - Museu Nacional, Universidade Federal do Rio de Janeiro, 1977.

IMBRIZI, Jaquelina Maria. A formação do indivíduo no capitalismo tardio: uma análise de estudos que vinculam a esfera subjetiva ao mundo do trabalho. São Paulo: Hucitec, 2005. 322p.

LAZZARATO, Maurizio; NEGRI, Antonio. Trabalho imaterial: formas de vida e produção de subjetividade. Tradução de Mônica Jesus. Rio de Janeiro: DP\&A Editora, 2001.

McPHERSON, Barry; CURTIS, James; LOY, John W. The social significance of sport: an introduction to the sociology of sport. Champaign, Illinois: Human Kinetics Books, 1989. $334 \mathrm{p}$.

MESZÁROS, István. A teoria da alienação em Marx. São Paulo: Boitempo, 2006. 296 p.

MARX, Karl. Elementos fundamentales para la critica de la economia política. Buenos Aires: Siglo XXI, 1974.

MARX, Karl. Manuscritos econômico-filosóficos e outros textos escolhidos. Seleção de textos de José Arthur Giannotti. 2. ed. São Paulo: Abril Cultural, 1978. (Os pensadores). 
MARX, Karl; ENGELS, Friedrich. A ideologia alemã. São Paulo: Martins Fontes, 1989. 97 p.

NEGRI, Antonio; HARDT, Michel. Multidão: guerra e democracia na era do império. Rio de Janeiro: Record, 2005.

REIS, José Veillard. Manual dos direitos e deveres do jogador de futebol. Rio de Janeiro: Palestra Edições, 1985.
RODRIGUES, Nelson. À sombra das chuteiras imortais. São Paulo: Cia das Letras, 1993.

- A pátria em chuteiras. Textos selecionados e notas de Ruy Castro.São Paulo: Cia das Letras, 1994.

ROMERO, Daniel. Marx e a técnica: um estudo dos manuscritos de 1861-1863. São Paulo: Expressão Popular, 2005. 248 p.

\title{
The Immateriality of the Soccer Player's Work: a Theoretical Interpretation
}

\begin{abstract}
This paper presents a theoretical interpretation of the soccer player based on the notion of immaterial work. Although the soccer player's expertise involves quantifiable and measurable aspects related to material work, such as salary, contract, working hours that consist of practice, matches and so on, there are subjective and immeasurable elements that are not quantifiable. The latter may be analyzed from two analytical dimensions: that of the subject who works and that of the product of his work. Therefore, in the soccer player's job, the subject's sports talent is a major issue to be considered, since it then becomes the main product of his work and of the collective intelligence: the sports event.
\end{abstract}

Key words: immaterial work; material work; sports talent; sports event; soccer player.

Data de recebimento do artigo: 30-05-2008

Data de aprovação do artigo: 05-09-2008 